\title{
A Hybrid Multiple Criteria Decision Making Model for Supplier Selection
}

\author{
Chung-Min Wu, ${ }^{1}$ Ching-Lin Hsieh, ${ }^{2}$ and Kuei-Lun Chang ${ }^{3}$ \\ ${ }^{1}$ Graduate Institute of Services and Technology Management, National Taipei University of Technology, \\ 1 Zhong Xiao E. Road, Section 3, Taipei 106, Taiwan \\ ${ }^{2}$ Graduate Institute of Industrial and Business Management, National Taipei University of Technology, \\ 1 Zhong Xiao E. Road, Section 3, Taipei 106, Taiwan \\ ${ }^{3}$ Department of Communications Management, Ming Chuan University, 250 Zhong Shan N. Road, \\ Section 5, Taipei 111, Taiwan
}

Correspondence should be addressed to Kuei-Lun Chang; cs821@yahoo.com.tw

Received 15 May 2013; Revised 15 July 2013; Accepted 1 August 2013

Academic Editor: Yi-Chung $\mathrm{Hu}$

Copyright (C) 2013 Chung-Min Wu et al. This is an open access article distributed under the Creative Commons Attribution License, which permits unrestricted use, distribution, and reproduction in any medium, provided the original work is properly cited.

\begin{abstract}
The sustainable supplier selection would be the vital part in the management of a sustainable supply chain. In this study, a hybrid multiple criteria decision making (MCDM) model is applied to select optimal supplier. The fuzzy Delphi method, which can lead to better criteria selection, is used to modify criteria. Considering the interdependence among the selection criteria, analytic network process (ANP) is then used to obtain their weights. To avoid calculation and additional pairwise comparisons of ANP, a technique for order preference by similarity to ideal solution (TOPSIS) is used to rank the alternatives. The use of a combination of the fuzzy Delphi method, ANP, and TOPSIS, proposing an MCDM model for supplier selection, and applying these to a real case are the unique features of this study.
\end{abstract}

\section{Introduction}

In this era of global competition, the modern business companies pay much attention to identify and select alternative supply sources. As a result, an effective supplier selection process is very vital [1]. Chu and Varma [2] also point out that suppliers are an important component of the supply chain. Their ability and performance largely determine the success or failure of the supply chain. Supplier selection process plays an important role and significant impact on purchasing management in supply chain. It is a complex MCDM problem which is affected by various conflicting factors [3]. In this paper, we utilize a hybrid MCDM model including: the fuzzy Delphi method, ANP, and TOPSIS, adjusted to the experts' professional consensus to select the optimal supplier. The advantage of the fuzzy Delphi method is its simplicity. All the expert opinions can be encompassed in one investigation. Hence, this method can create more effective criteria selection [4]. ANP produces more accurate weighting of criteria, since it enables consideration of the dependence among factors in decision-making problems. Unfortunately, ANP requires many pairwise comparisons depending on the number and interdependence of factors and alternatives. This disadvantage of ANP is eliminated via the use of TOPSIS. Thus, the selection process is shortened [5]. By combining the fuzzy Delphi method, ANP, and TOPSIS, this study can make better decisions in selecting a supplier within a shorter time, which distinguishes this study from others in the literature. The organization of this paper is as follows. We first present a literature review of the supplier selection. Next, the fuzzy Delphi method, ANP, and TOPSIS as selection tools are described. The integrated method within the context of selecting the optimal supplier is shown in Section 6. The conclusion is given in Section 7.

\section{MCDM Methods for Supplier Selection}

Supplier selection is a common problem for acquiring the necessary materials to support the output of organizations. 
The problem is to find and evaluate the most optimal supplier on the basis of various suppliers' capabilities [2]. A number of published researches emphasized the supplier selection. In this section, we limit our literature review to the works where MCDM approaches applied in supplier selection are considered. Amindoust et al. [6] apply fuzzy logic and propose a new ranking method based on fuzzy inference system (FIS) for supplier selection. Chu and Varma [2] apply multiple levels MCDM model under fuzzy environment to evaluate and select suppliers. Erdem and Göçen [7] employ analytic hierarchy process (AHP) to evaluate suppliers. A goal programming (GP) model is then applied for order allocation. Vahdani et al. [8] propose a new intelligent model based on the locally linear neurofuzzy (LLNF) with locally linear model tree (LOLIMOT) to predict the performance rating of the suppliers in cosmetics industry. Zouggari and Benyoucef [1] use fuzzy AHP to select suppliers. Thereafter, fuzzy TOPSIS is utilized to determine the weights for order allocation among selected suppliers. Omurca [3] develops an effective hybrid system by fuzzy c-means (FCM) and rough set theory (RST) to solve supplier selection, evaluation, and development problems.

It is difficult to find the best approach to select suppliers, so the companies use different methods to deal with it. However, the most vital issue in the process of supplier selection is to develop a suitable method to select the right supplier [11]. This paper firstly adopts the fuzzy Delphi method to identify the selection criteria. The assumption of independence of criteria is not always correct because in real world the criteria are often dependent on each other [12]. To address this issue, ANP, which captures the interdependence, is applied to generate the weights of the selection criteria. TOPSIS is used to rank the alternatives. By combining the fuzzy Delphi method, ANP, and TOPSIS, this study can make better decisions in supplier selection.

\section{The Fuzzy Delphi Method}

The Delphi method is a traditional forecasting approach that does not require large samples. It can be utilized to generate a professional consensus for complex topics [13]. The Delphi method suffers from low convergence expert opinions and more execution cost. Murray et al. [14] integrate the Delphi method and fuzzy theory. Membership degree is applied to establish the membership function of each participant. Ishikawa et al. [15] also introduce fuzzy theory into the Delphi method. Max-min and fuzzy integration algorithm is developed. Hsu and Yang [16] apply a triangular fuzzy number to encompass expert opinions and establish a fuzzy Delphi method. The max and min values of expert opinions are taken as the 2 terminal points of triangular fuzzy numbers, and the geometric mean is taken as the membership degree of triangular fuzzy numbers to derive the statistical unbiased effect and avoid the impact of extreme values. Kuo and Chen [17] point out that the advantage of the fuzzy Delphi method for collecting group decision is that every expert opinion can be considered and integrated to achieve the consensus of group decisions. Moreover, it reduces the time of investigation and the consumption of cost and time. Ma et al. [4] describe that the advantage of the fuzzy Delphi method is its simplicity. All the expert opinions can be encompassed in one investigation. Hence, this method can create more effective criteria selection. This paper adopts the fuzzy Delphi method to identify the selection criteria for supplier. The geometric mean of each criterion is used to denote the consensus of the experts' evaluation value of the criteria [16].

Consider the following:

$$
L_{G}=\left(L_{1} \times L_{2} \times \cdots \times L_{n}\right)^{1 / n}
$$

where $L_{n}$ is the importance rating of the criteria by $n$th experts, while $L_{G}$ is the geometric mean value.

\section{ANP}

ANP is a comprehensive decision-making technique that captures the outcome of dependency between criteria. AHP serves as a starting point of ANP. Priorities are established in the same way that they are in AHP using pairwise comparisons. ANP comprises 4 major steps [18].

Step 1. Construct hierarchy and structure problem. Structure the problem in a hierarchy of different levels constituting goal, perspective, criteria, and alternatives. The hierarchy which is comprised of a goal, levels of elements, and connections between the elements can be determined by decision makers' opinions via brainstorming or other appropriate methods such as the literature reviewing.

Step 2. Determine the perspectives and criteria weights. In this step, the decision-making committee makes a series of pairwise comparisons to establish the relative importance of perspectives and criteria. In these comparisons, a 1-9 scale is applied to compare 2 perspectives or criteria according to the interdependency of perspectives and criteria. The eigenvector of the observable pairwise comparison matrix provides the perspectives and criteria weights at this level, which will be used in the supermatrix. Saaty [19] proposes the consistency ratio (C.R.) to verify the consistency of the pairwise comparison matrix. If C.R. value $\leq 0.1$, the consistency of the pairwise comparison matrix is accepted.

Step 3. Construct and solve the supermatrix. The supermatrix concept is similar to the Markov chain process. The perspectives and criteria weights derived from Step 2 are used to obtain the column of the supermatrix. Finally, the supermatrix will be stabilized by multiplying the supermatrix by itself until the supermatrix's row values converge to the same value for each column of the matrix. We call the result the limiting matrix.

Step 4. Select the best alternative. According to the limiting matrix and weights of alternatives with respect to criteria, we can aggregate the total weight of each alternative. We rank the alternative according to their priority weights. 
In the previous literatures regarding the application of ANP, Azimi et al. [12] apply strengths, weaknesses, opportunities, and threats (SWOT) analysis to assign feasible strategies. ANP and TOPSIS are used to rank the strategies for Iranian mining sector. Liao et al. [20] use ANP, and TOPSIS for assessing the performance of Taiwanese tour guides. Fazli and Jafari [21] apply decision-making trial and evaluation laboratory (DEMATEL), ANP and VlseKriterijumska Optimizacija I Kompromisno Resenje (VIKOR) to select the best alternative for investment in stock exchange. Hu et al. [22] use ANP to evaluate the performance of Taiwanese homestay industry. Kang et al. [23] apply fuzzy ANP and interpretive structural modeling (ISM) to select technologies for new product development (NPD). Lee [24] uses fuzzy ANP for competitive strategy selection. Y. H. Lee and Y. H. Lee [25] apply ANP to select the most suitable competitive strategy for multinational biotech pharmaceutical enterprises. Wang et al. [26] construct a project selection model on the basis of the fuzzy Delphi method, ISM, and ANP.

The assumption of independence of criteria is not always correct because in real world the criteria are often dependent on each other [12]. ANP, widely applied in decision making, is more accurate and feasible under interdependent situations. ANP appears to be one of the more feasible and accurate solutions for generating the weights of the criteria.

\section{TOPSIS}

TOPSIS, proposed by Hwang and Yoon in 1981, enables decision makers to determine the positive ideal solution $\left(A^{*}\right)$ and negative ideal solution $\left(A^{-}\right)$. On the basis of TOPSIS, the chosen alternative should have the shortest distance from the positive ideal solution and farthest from the negative ideal solution [27]. The computation procedure is presented as follows.

Step 1. Construct the standardized appraisal matrix

$$
r_{i j}=\frac{x_{i j}}{\sqrt{\sum_{i=1}^{m} x_{i j}^{2}}}
$$

where $i$ indicates the alternatives, $j$ denotes the selecting criteria, and $x_{i j}$ means the $i$ alternative under the $j$ criterion to be assessed.

Step 2. Construct the weighted standardized appraisal matrix. Weights of selection criteria, $w=\left(w_{1}, w_{2}, \ldots, w_{n}\right)$, multiplied by standardized appraisal matrix can be expressed as

$$
v=\left[\begin{array}{cccc}
v_{11} & v_{12} & \ldots & v_{1 n} \\
v_{21} & v_{22} & \ldots & v_{2 n} \\
\vdots & \vdots & \ldots & \vdots \\
v_{m 1} & v_{m 2} & \cdots & v_{n m}
\end{array}\right]=\left[\begin{array}{cccc}
w_{1} r_{11} & w_{2} r_{12} & \ldots & w_{n} r_{1 n} \\
w_{1} r_{21} & w_{2} r_{22} & \ldots & w_{n} r_{2 n} \\
\vdots & \vdots & \ldots & \vdots \\
w_{1} r_{m 1} & w_{2} r_{m 2} & \cdots & w_{n} r_{m n}
\end{array}\right] .
$$

Step 3. Identify the positive ideal solution and negative ideal solution

$$
\begin{aligned}
A^{*} & =\left\{v_{1}^{*}, v_{2}^{*}, \ldots, v_{j}^{*}, \ldots, v_{n}^{*}\right\} \\
& =\left\{\left(\max _{i} v_{i j} \mid j \in J\right) \mid i=1, \ldots, m\right\}, \\
A^{-} & =\left\{v_{1}^{-}, v_{2}^{-}, \ldots, v_{j}^{-}, \ldots, v_{n}^{-}\right\} \\
& =\left\{\left(\min _{i} v_{i j} \mid j \in J\right) \mid i=1, \ldots, m\right\} .
\end{aligned}
$$

Step 4. Calculate the Euclidean distance between the positive ideal solution $\left(S_{i}^{*}\right)$ and negative ideal solution $\left(S_{i}^{-}\right)$for each alternative

$$
\begin{aligned}
& S_{i}^{*}=\sqrt{\sum_{j=1}^{n}\left(v_{i j}-v_{i}^{*}\right)^{2}}, \quad i=1, \ldots, m, \\
& S_{i}^{-}=\sqrt{\sum_{j=1}^{n}\left(v_{i j}-v_{i}^{-}\right)^{2}}, \quad i=1, \ldots, m .
\end{aligned}
$$

Step 5. Calculate the relative closeness to the positive ideal solution for each alternative:

$$
C_{i}^{*}=\frac{S_{i}^{-}}{S_{i}^{*}+S_{i}^{-}} .
$$

An alternative $A_{i}$ is closer to $A^{*}$ and farther from $A^{-}$as $C_{i}^{*}$ approaches to 1.

Step 6. Rank the preference order by $C_{i}^{*}$. According to $C_{i}^{*}$, larger index values indicate better performance of the alternatives.

According to the literatures regarding the application of TOPSIS, Azimi et al. [12] apply SWOT analysis to assign feasible strategies. ANP and TOPSIS are used to rank the strategies for Iranian mining sector. Liao et al. [20] use ANP and TOPSIS for assessing the performance of Taiwanese tour guides. Choudhary and Shankar [28] use fuzzy AHP and TOPSIS to select locations for thermal power plants. Ishizaka et al. [29] select the location of a casino in the Greater London region using the Weighted Sum Method, TOPSIS, and the preference ranking organization method for enrichment evaluation (PROMETHEE). Although TOPSIS is comprehensible and the computations are uncomplicated, it suffers from the inherent problem of assigning reliable subjective preferences to criteria [30]. Due to the interdependent criteria, ANP is applied in this paper to generate the weights for the selection criteria. TOPSIS is used to rank the alternatives.

\section{The Implementation of Proposed Model}

We employ the fuzzy Delphi method, ANP, and TOPSIS in a TV-shopping company to select optimal product supplier. In 2004, case company and LOTTE, a Korean TV-shopping 


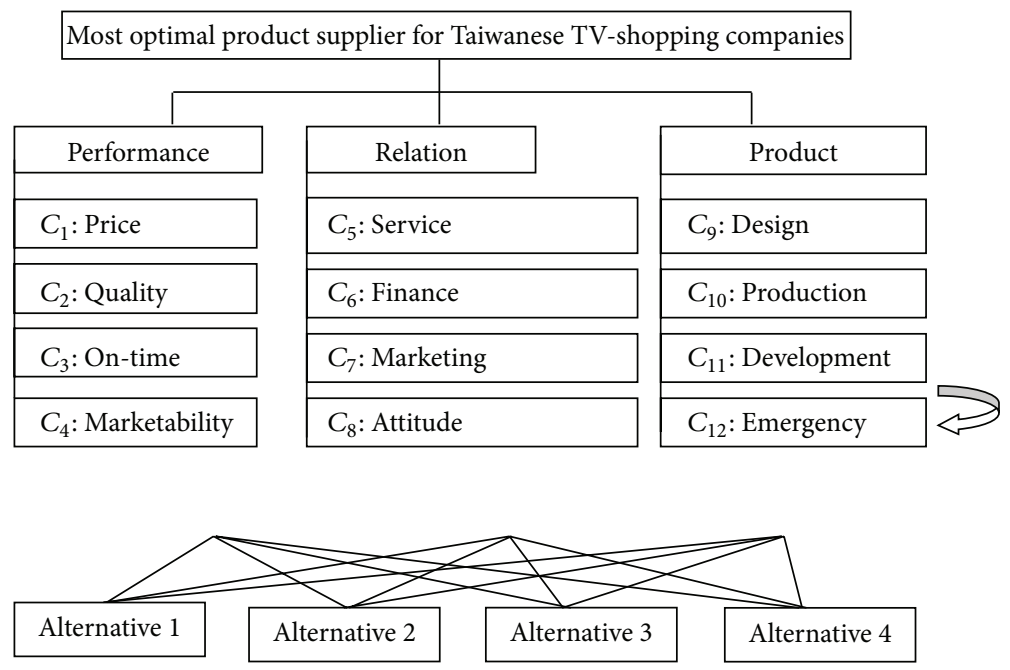

FIGURE 1: Hierarchy for Taiwanese TV-shopping companies to select product suppliers.

TABLE 1: Statistics for the selection criteria.

\begin{tabular}{lc}
\hline Criteria & Geometric mean values \\
\hline Attitude & 6.1143 \\
Environmental costs & 5.3163 \\
Quality & 5.7187 \\
Environmental management system & 5.2631 \\
Resource consumption & 5.3614 \\
Marketability & 5.9705 \\
Storage space & 5.3307 \\
Distance & 5.2988 \\
Finance & 6.3497 \\
Pollution control & 5.2622 \\
Marketing & 5.8271 \\
Terms of payment & 5.2502 \\
Product variety & 5.1622 \\
Design & 5.9463 \\
Production & 5.8908 \\
Work experience & 5.1215 \\
Development & 6.2979 \\
Professional workforce & 5.4749 \\
Emergency & 5.7971 \\
Information disclosure & 5.2179 \\
Price & 5.7971 \\
The rights of stakeholders & 5.2179 \\
On-time & 5.8415 \\
Service & 6.0287 \\
\hline
\end{tabular}

channel, cofounded a corporation. Now, it has 3 shopping channels broadcasted on TV for 24 hours a day. Moreover, the case company also has 53 cosmeceuticals stores and a department store. The employment of the case company is more than 1500 . The decision committee includes 3 managers, including a director of overseas product marketing department and 2 directors of product development department. There are 4 product suppliers of cosmetics as alternatives. We depict the selecting process as follow.

Step 1. Construct hierarchy and structure problem. By interviewing executives in the TV-shopping industry and reviewing studies about supplier selection, we collect the criteria showing in Table 1. The uzzy Delphi method can create better criteria selection $[4,16]$. We apply the concept of the fuzzy Delphi method to revise the criteria.

Questionnaires based on Likert 9 point scale, with 1 as most unimportant and 9 as most important, are sent to 48 senior executives to obtain their opinions about the importance of criteria. In this paper, the geometric mean of each criterion is used to denote the consensus of the experts' evaluation value of the criteria. According to the geometric mean value of each criterion, we retain the top 12 showing in Table 2. Based on Jain et al. [9], Amindoust et al. [6], Zouggari and Benyoucef [1], and discussion with senior executives, 12 criteria are taken into 3 perspectives, namely performance, relation, and product to structure the hierarchy for Taiwanese TV-shopping companies to select product suppliers, as shown in Figure 1. After reviewing executives, in this paper, we treat the 3 perspectives as independent. The criteria within each perspective have interdependence relationships.

Step 2. Determine the perspectives and criteria weights. In this step, the decision-making committee makes a series of pairwise comparisons to establish the relative importance of perspectives. In these comparisons, a 1-9 scale is applied to 
TABLE 2: Descriptions of the selection criteria.

\begin{tabular}{|c|c|c|}
\hline Criteria & Definition & Contributors \\
\hline Price & The price of the product & {$[1-3,6]$} \\
\hline Quality & The quality of the product & {$[1-3,6]$} \\
\hline On-time & On-time delivery & {$[1-3,6,7]$} \\
\hline Marketability & The marketability of the product & {$[9]$} \\
\hline Service & The service after sale & {$[1,6-8]$} \\
\hline Finance & The financial status of the supplier & {$[1,2,6]$} \\
\hline Marketing & The marketing resource of the supplier & Senior executives propose \\
\hline Attitude & The attitude of the supplier & {$[10]$} \\
\hline Design & The design capacity of the supplier & {$[2,3]$} \\
\hline Production & The production capacity of the supplier & {$[2,3,6]$} \\
\hline Development & The NPD capacity of the supplier & {$[1-3,6,7]$} \\
\hline Emergency & The capacity of the supplier to fill emergency orders & {$[10]$} \\
\hline
\end{tabular}

TABLE 3: The pairwise comparisons of perspectives.

\begin{tabular}{lcccc}
\hline & \multicolumn{4}{c}{$\lambda_{\max }=3.0000$, C.R. $=0.0000$} \\
& Performance & Relation & Product & Priority weights \\
\hline Performance & 1.0000 & 1.8171 & 0.9283 & 0.3812 \\
Relation & 0.5503 & 1.0000 & 0.5228 & 0.2114 \\
Product & 1.0772 & 1.9129 & 1.0000 & 0.4075 \\
\hline
\end{tabular}

compare the 2 perspectives. The pairwise comparison matrix and the development of each perspective priority weight are shown in Table 3. According to the interdependency of criteria, we apply pairwise comparisons again to establish the criteria relationships within each perspective. The eigenvector of the observable pairwise comparison matrix provides the criteria weights at this level, which will be used in the supermatrix. With respect to price, for example, a pairwise comparison within the performance perspective can be shown in Table 4. According to this way, we can derive every criterion weight to obtain the supermatrix.

Step 3. Construct and solve the supermatrix. The criteria weights derived from Step 2 are used to get the column of the supermatrix as shown in Table 5. Finally, the system solution is derived by multiplying the supermatrix of model variables by itself, which accounts for variable interaction, until the system's row values converge to the same value for each column of the matrix, as shown in Table 6. According to Table 3 and Table 6 , we can aggregate the total weight of each criterion as shown in Table 7.

Step 4. Construct the standardized and weighted standardized appraisal matrix. The decision-making committee is
TABLE 4: The pairwise comparisons within performance perspective with respect to price.

$$
\lambda_{\max }=3.0059, \text { C.R. }=0.0045
$$

Quality On-time Marketability Priority weights

\begin{tabular}{lllll}
\hline Quality & 1.0000 & 2.7144 & 1.8821 & 0.5291 \\
On-time & 0.3684 & 1.0000 & 0.8736 & 0.2105 \\
Marketability & 0.5313 & 1.1447 & 1.0000 & 0.2603 \\
\hline
\end{tabular}

asked to establish the appraisal matrix by comparing 4 alternatives with respect to each criterion. After the appraisal matrix is generated, utilize (2) to obtain standardized appraisal matrix, showing in Table 8 . The criteria weights derived from ANP showing in Table 7 are multiplied by standardized appraisal matrix to get the weighted standardized appraisal matrix.

Step 5. Identify the positive ideal solution and negative ideal solution. The positive ideal solution and negative ideal solution are defined according to (4) as

$$
\begin{aligned}
& A^{*}=(0.0371,0.0646,0.0443,0.0456,0.0319,0.0256, \\
& 0.0278,0.0356,0.0701,0.0556,0.0462,0.0574), \\
& A^{-}=(0.0736,0.0498,0.0279,0.0409,0.0234,0.0155, \\
& 0.0197,0.0281,0.0540,0.0428,0.0343,0.0446) .
\end{aligned}
$$

Step 6. Calculate the Euclidean distance between the positive ideal solution and negative ideal solution for each alternative. The Euclidean distance between the positive ideal solution and negative ideal solution for each alternative can be measured by (5). 
TABLE 5: The supermatrix before convergence.

\begin{tabular}{|c|c|c|c|c|c|c|c|c|c|c|c|c|}
\hline & $C_{1}$ & $C_{2}$ & $C_{3}$ & $C_{4}$ & $C_{5}$ & $C_{6}$ & $C_{7}$ & $C_{8}$ & $C_{9}$ & $C_{10}$ & $C_{11}$ & $C_{12}$ \\
\hline$C_{1}$ & 0.0000 & 0.4718 & 0.2794 & 0.5066 & & & & & & & & \\
\hline$C_{2}$ & 0.5291 & 0.0000 & 0.3303 & 0.2750 & & & & & & & & \\
\hline$C_{3}$ & 0.2105 & 0.2886 & 0.0000 & 0.2183 & & & & & & & & \\
\hline$C_{4}$ & 0.2603 & 0.2396 & 0.3903 & 0.0000 & & & & & & & & \\
\hline$C_{5}$ & & & & & 0.0000 & 0.3244 & 0.2518 & 0.4416 & & & & \\
\hline$C_{6}$ & & & & & 0.2518 & 0.0000 & 0.2845 & 0.2391 & & & & \\
\hline$C_{7}$ & & & & & 0.2845 & 0.2693 & 0.0000 & 0.3193 & & & & \\
\hline$C_{8}$ & & & & & 0.4636 & 0.4063 & 0.4636 & 0.0000 & & & & \\
\hline$C_{9}$ & & & & & & & & & 0.0000 & 0.4382 & 0.2635 & 0.6027 \\
\hline$C_{10}$ & & & & & & & & & 0.2706 & 0.0000 & 0.4879 & 0.2554 \\
\hline$C_{11}$ & & & & & & & & & 0.3682 & 0.1905 & 0.0000 & 0.1418 \\
\hline$C_{12}$ & & & & & & & & & 0.3613 & 0.3713 & 0.2486 & 0.0000 \\
\hline
\end{tabular}

TABLE 6: The supermatrix after convergence.

\begin{tabular}{|c|c|c|c|c|c|c|c|c|c|c|c|c|}
\hline & $C_{1}$ & $C_{2}$ & $C_{3}$ & $C_{4}$ & $C_{5}$ & $\mathrm{C}_{6}$ & $C_{7}$ & $C_{8}$ & $C_{9}$ & $C_{10}$ & $C_{11}$ & $C_{12}$ \\
\hline$C_{1}$ & 0.3005 & 0.3005 & 0.3005 & 0.3005 & & & & & & & & \\
\hline$C_{2}$ & 0.2840 & 0.2840 & 0.2840 & 0.2840 & & & & & & & & \\
\hline$C_{3}$ & 0.1937 & 0.1937 & 0.1937 & 0.1937 & & & & & & & & \\
\hline$C_{4}$ & 0.2219 & 0.2219 & 0.2219 & 0.2219 & & & & & & & & \\
\hline$C_{5}$ & & & & & 0.2598 & 0.2598 & 0.2598 & 0.2598 & & & & \\
\hline$C_{6}$ & & & & & 0.2040 & 0.2040 & 0.2040 & 0.2040 & & & & \\
\hline$C_{7}$ & & & & & 0.2274 & 0.2274 & 0.2274 & 0.2274 & & & & \\
\hline$C_{8}$ & & & & & 0.3088 & 0.3088 & 0.3088 & 0.3088 & & & & \\
\hline$C_{9}$ & & & & & & & & & 0.3096 & 0.3096 & 0.3096 & 0.3096 \\
\hline$C_{10}$ & & & & & & & & & 0.2435 & 0.2435 & 0.2435 & 0.2435 \\
\hline$C_{11}$ & & & & & & & & & 0.1960 & 0.1960 & 0.1960 & 0.1960 \\
\hline$C_{12}$ & & & & & & & & & 0.2510 & 0.2510 & 0.2510 & 0.2510 \\
\hline
\end{tabular}

TABLE 7: The total weight of each criterion.

\begin{tabular}{lccc}
\hline & $\begin{array}{c}\text { Weights from } \\
\text { perspectives }\end{array}$ & $\begin{array}{c}\text { Weights from supermatrix } \\
\text { after convergence }\end{array}$ & $\begin{array}{c}\text { Total weights } \\
\text { of criteria }\end{array}$ \\
\hline$C_{1}$ & 0.3812 & 0.3005 & 0.1145 \\
$C_{2}$ & 0.3812 & 0.2840 & 0.1082 \\
$C_{3}$ & 0.3812 & 0.1937 & 0.0738 \\
$C_{4}$ & 0.3812 & 0.2219 & 0.0846 \\
$C_{5}$ & 0.2114 & 0.2598 & 0.0549 \\
$C_{6}$ & 0.2114 & 0.2040 & 0.0431 \\
$C_{7}$ & 0.2114 & 0.2274 & 0.0481 \\
$C_{8}$ & 0.2114 & 0.3088 & 0.0653 \\
$C_{9}$ & 0.4075 & 0.3096 & 0.1261 \\
$C_{10}$ & 0.4075 & 0.2435 & 0.0992 \\
$C_{11}$ & 0.4075 & 0.1960 & 0.0798 \\
$C_{12}$ & 0.4075 & 0.2510 & 0.1023 \\
\hline
\end{tabular}

Step 7. Calculate the relative closeness to the positive ideal solution for each alternative. $C_{i}^{*}$ value of each alternativecan be obtained by (6).
Step 8. Select the best alternative. According to Table 9, the optimal product supplier is selected. Therefore, it is obvious that the ranking for the optimal product suppliers is Alternative 4, Alternative 1, Alternative 3, and Alternative 2.

\section{Conclusion}

Researchers who carry out in the field of supplier selection have been utilizing MCDM methods. This study presents an effective model applying the fuzzy Delphi method, ANP, and TOPSIS to select the optimal supplier, which distinguishes this study from others in the literature. The fuzzy Delphi method is used to revise the criteria. To solve the problem of selection criteria interdependency, ANP is used to obtain the weights of the criteria. To prevent excessive calculation and additional pairwise comparisons of ANP, TOPSIS is used to rank the alternatives. TOPSIS eliminates many procedures that are performed in ANP and enables the system to reach a conclusion in a shorter time. In this paper, the C.R. of each pairwise comparison is less than 0.1 , which means that the reliability of the data is acceptable. By combining the fuzzy Delphi method, ANP, and TOPSIS, this study can make better 
TABLE 8: Standardized appraisal matrix.

\begin{tabular}{cccccccccccccc}
\hline & $C_{1}$ & $C_{2}$ & $C_{3}$ & $C_{4}$ & $C_{5}$ & $C_{6}$ & $C_{7}$ & $C_{8}$ & $C_{9}$ & $C_{10}$ & $C_{11}$ & $C_{12}$ \\
\hline$A_{1}$ & 0.5140 & 0.5967 & 0.5997 & 0.4838 & 0.5807 & 0.4533 & 0.5434 & 0.5251 & 0.4279 & 0.4650 & 0.4562 & 0.5331 \\
$A_{2}$ & 0.6425 & 0.4597 & 0.5449 & 0.5398 & 0.5191 & 0.5939 & 0.5775 & 0.4299 & 0.4794 & 0.5323 & 0.5787 & 0.4590 \\
$A_{3}$ & 0.4670 & 0.4704 & 0.3778 & 0.4904 & 0.4597 & 0.3597 & 0.4509 & 0.4921 & 0.5277 & 0.5604 & 0.4293 & 0.4360 \\
$A_{4}$ & 0.3238 & 0.4597 & 0.4479 & 0.4838 & 0.4267 & 0.5589 & 0.4097 & 0.5453 & 0.5555 & 0.4317 & 0.5222 & 0.5613 \\
\hline
\end{tabular}

TABLE 9: Results of TOPSIS.

\begin{tabular}{ccccc}
\hline & $S_{i}^{*}$ & $S_{i}^{-}$ & $C_{i}^{*}$ & Rank \\
\hline$A_{1}$ & 0.0315 & 0.0314 & 0.4995 & 2 \\
$A_{2}$ & 0.0430 & 0.0256 & 0.3736 & 4 \\
$A_{3}$ & 0.0354 & 0.0274 & 0.4361 & 3 \\
$A_{4}$ & 0.0263 & 0.0444 & 0.6281 & 1 \\
\hline
\end{tabular}

decisions in selecting the supplier. The main contributions of this work are summarized as follows.

(1) The selection criteria are collected through the literatures and interviews with senior executives; the fuzzy Delphi method which can create a better criteria selection is used to revise the criteria. By this way, we can obtain more accurate criteria.

(2) To solve the problem of selection criteria interdependency, ANP is used to obtain the weights of the criteria. TOPSIS eliminates many procedures that are performed in ANP and enables the system to reach a conclusion in a shorter time.

(3) The proposed model has increased the efficiency of the decision-making process in supplier selection. It can be executed in any companies.

(4) The hierarchy including 3 perspectives and 12 criteria can help Taiwanese TV-shopping companies to select product suppliers more effectively.

This study is conducted with expert sample groups. A larger sample that brings more explanatory power may have allowed more sophisticated evaluation analysis. Moreover, we only consider interdependence relationships among criteria within each perspective. We suggest that future research studies consider more complex relationships among criteria or perspectives and incorporate more criteria in order to make more accurate estimates. Besides, some criteria could have a qualitative structure or have an uncertain structure which cannot be measured precisely. In such cases, fuzzy numbers can be applied to obtain the evaluation matrix. In other words, ANP and TOPSIS ignore the fuzziness of the executives' judgment during the decision-making process. We suggest that follow-up researchers analyze this topic with the concept of fuzzy sets.

\section{References}

[1] A. Zouggari and L. Benyoucef, "Simulation based fuzzy TOPSIS approach for group multi-criteria supplier selection problem," Engineering Applications of Artificial Intelligence, vol. 25, no. 3, pp. 507-519, 2012.

[2] T. Chu and R. Varma, "Evaluating suppliers via a multiple levels multiple criteria decision making method under fuzzy environment," Computers and Industrial Engineering, vol. 62, no. 2, pp. 653-660, 2012.

[3] S. I. Omurca, "An intelligent supplier evaluation, selection and development system," Applied Soft Computing, vol. 13, pp. 690697, 2013.

[4] Z. Ma, C. Shao, S. Ma, and Z. Ye, "Constructing road safety performance indicators using fuzzy delphi method and grey delphi method," Expert Systems with Applications, vol. 38, no. 3, pp. 1509-1514, 2011.

[5] M. Dağdeviren, "A hybrid multi-criteria decision-making model for personnel selection in manufacturing systems," Journal of Intelligent Manufacturing, vol. 21, no. 4, pp. 451-460, 2010.

[6] A. Amindoust, S. Ahmed, A. Saghafinia, and A. Bahreininejad, "Sustainable supplier selection: a ranking model based on fuzzy inference system," Applied Soft Computing Journal, vol. 12, no. 6, pp. 1668-1677, 2012.

[7] A. S. Erdem and E. Göçen, "Development of a decision support system for supplier evaluation and order allocation," Expert Systems with Applications, vol. 39, no. 5, pp. 4927-4937, 2012.

[8] B. Vahdani, S. H. Iranmanesh, S. M. Mousavi, and M. Abdollahzade, "A locally linear neuro-fuzzy model for supplier selection in cosmetics industry," Applied Mathematical Modelling, vol. 36, no. 10, pp. 4714-4727, 2012.

[9] V. Jain, S. Wadhwa, and S. G. Deshmukh, "Supplier selection using fuzzy association rules mining approach," International Journal of Production Research, vol. 45, no. 6, pp. 1323-1353, 2007.

[10] S. Şen, H. Başligil, C. G. Şen, and H. Baraçli, "A framework for defining both qualitative and quantitative supplier selection criteria considering the buyer-supplier integration strategies," International Journal of Production Research, vol. 46, no. 7, pp. 1825-1845, 2008. 
[11] C. Chen, C. Lin, and S. Huang, "A fuzzy approach for supplier evaluation and selection in supply chain management," International Journal of Production Economics, vol. 102, no. 2, pp. 289301, 2006.

[12] R. Azimi, A. Yazdani-Chamzini, M. M. Fouladgar, E. K. Zavadskas, and M. H. Basiri, "Ranking the strategies of mining sector through ANP and TOPSIS in a SWOT framework," Journal of Business Economics and Management, vol. 12, no. 4, pp. 670-689, 2011.

[13] A. Hartman, "Reaching consensus using the Delphi technique," Educational Leadership, vol. 38, no. 6, pp. 495-497, 1981.

[14] T. J. Murray, L. L. Pipino, and J. P. Gigch, "A pilot study of fuzzy set modification of Delphi," Human Systems Management, vol. 5, no. 1, pp. 76-80, 1985.

[15] A. Ishikawa, M. Amagasa, T. Shiga, G. Tomizawa, R. Tatsuta, and H. Mieno, "The max-min Delphi method and fuzzy Delphi method via fuzzy integration," Fuzzy Sets and Systems, vol. 55, no. 3, pp. 241-253, 1993 .

[16] T. H. Hsu and T. H. Yang, "Application of fuzzy analytic hierarchy process in the selection of advertising media," Journal of Management and Systems, vol. 7, no. 1, pp. 19-40, 2000.

[17] Y. Kuo and P. Chen, "Constructing performance appraisal indicators for mobility of the service industries using Fuzzy Delphi method," Expert Systems with Applications, vol. 35, no. 4, pp. 1930-1939, 2008.

[18] T. L. Saaty, Decision Making with Dependence and Feedback: The Analytic Network Process, RWS Publication, Pittsburgh, Pa, USA, 1996.

[19] T. L. Saaty, The Analytic Hierarchy Process, McGraw-Hill, New York, NY, USA, 1980.

[20] S. K. Liao, Y. C. Chen, K. L. Chang, and T. W. Tseng, "Assessing the performance of Taiwanese tour guides," African Journal of Business Management, vol. 5, no. 4, pp. 1325-1333, 2011.

[21] S. Fazli and H. Jafari, "Developing a hybrid multi-criteria model for investment in stock exchange," Management Science Letters, vol. 2, pp. 457-468, 2012.

[22] Y. C. Hu, J. H. Wang, and R. Y. Wang, "Evaluating the performance of Taiwan homestay using analytic network process," Mathematical Problems in Engineering, vol. 2012, Article ID 827193, 24 pages, 2012.

[23] H. Y. Kang, A. H. I. Lee, C. C. Chang, and M. S. Kang, "A model for selecting technologies in new product development," Mathematical Problems in Engineering, vol. 2012, Article ID 358129, 17 pages, 2012.

[24] Y. H. Lee, "A fuzzy analytic network process approach to determining prospective competitive strategy in China: a case study for multinational biotech pharmaceutical enterprises," Journal of Business Economics and Management, vol. 13, no. 1, pp. 5-28, 2012.

[25] Y. H. Lee and Y. H. Lee, "Integrated assessment of competitivestrategy selection with an analytical network process," Journal of Business Economics and Management, vol. 13, no. 5, pp. 801-831, 2012.

[26] W. M. Wang, A. H. I. Lee, L. P. Peng, and Z. L. Wu, "An integrated decision making model for district revitalization and regeneration project selection," Decision Support Systems, vol. 54, pp. 1092-1103, 2013.

[27] C. L. Hwang and K. Yoon, Multiple Attribute Decision Making: Methods and Application, Springer, New York, NY, USA, 1981.

[28] D. Choudhary and R. Shankar, "An STEEP-fuzzy AHP-TOPSIS framework for evaluation and selection of thermal power plant location: a case study from India," Energy, vol. 42, pp. 510-521, 2012.

[29] A. Ishizaka, P. Nemery, and K. Lidouh, "Location selection for the construction of a casino in the Greater London region: a triple multi-criteria approach," Tourism Management, vol. 34, pp. 211-220, 2013.

[30] H. Shyur, "COTS evaluation using modified TOPSIS and ANP," Applied Mathematics and Computation, vol. 177, no. 1, pp. 251259, 2006. 


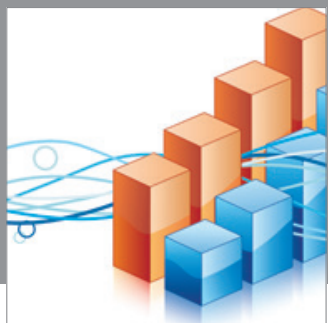

Advances in

Operations Research

mansans

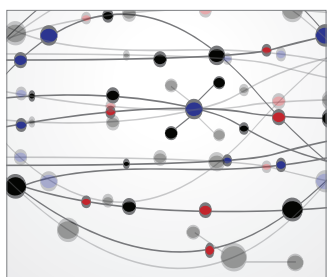

The Scientific World Journal
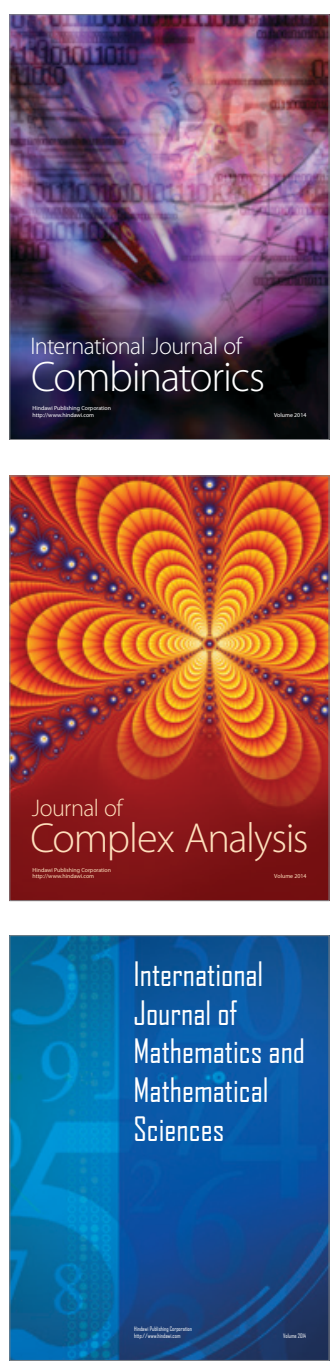
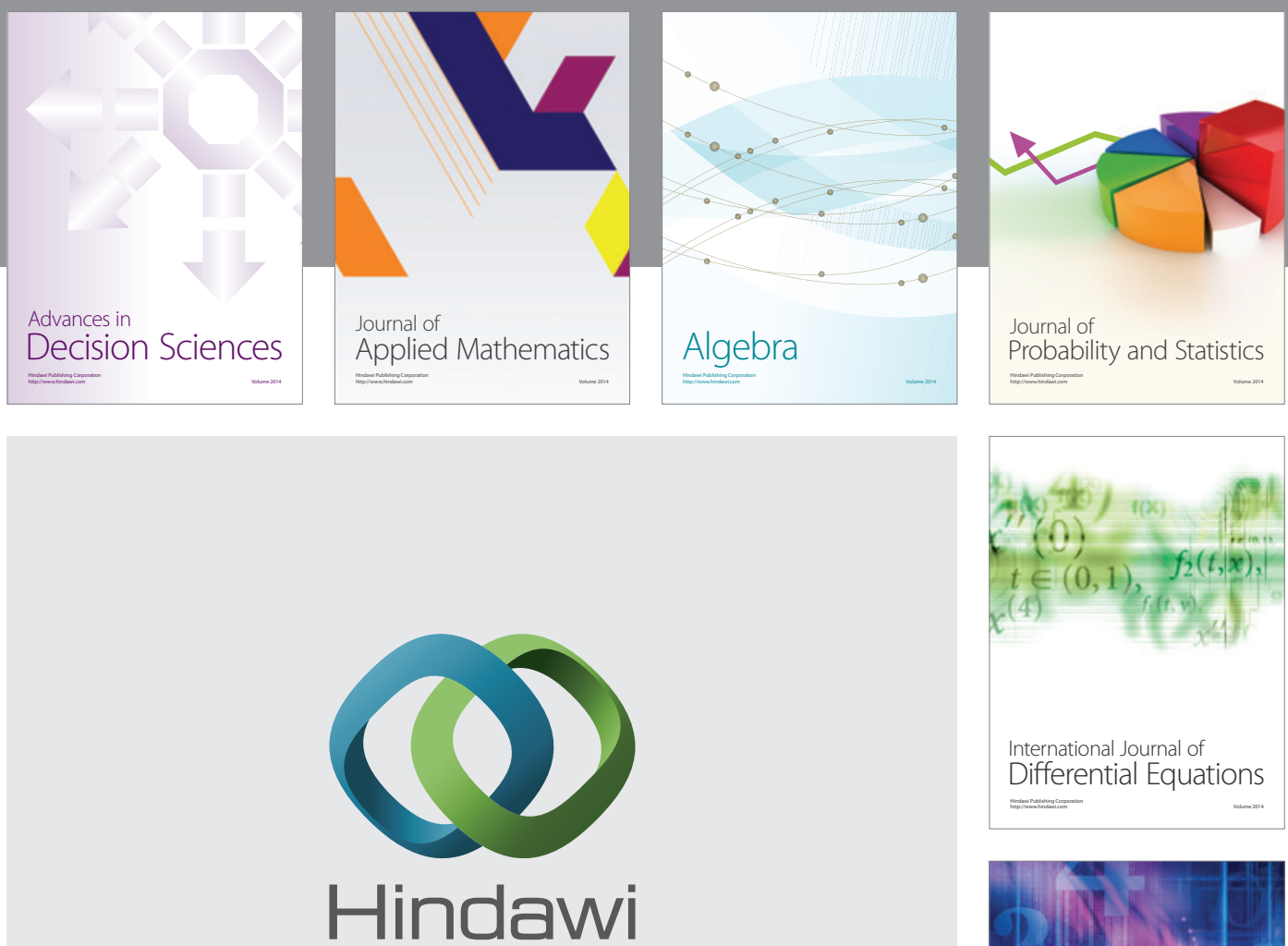

Submit your manuscripts at http://www.hindawi.com
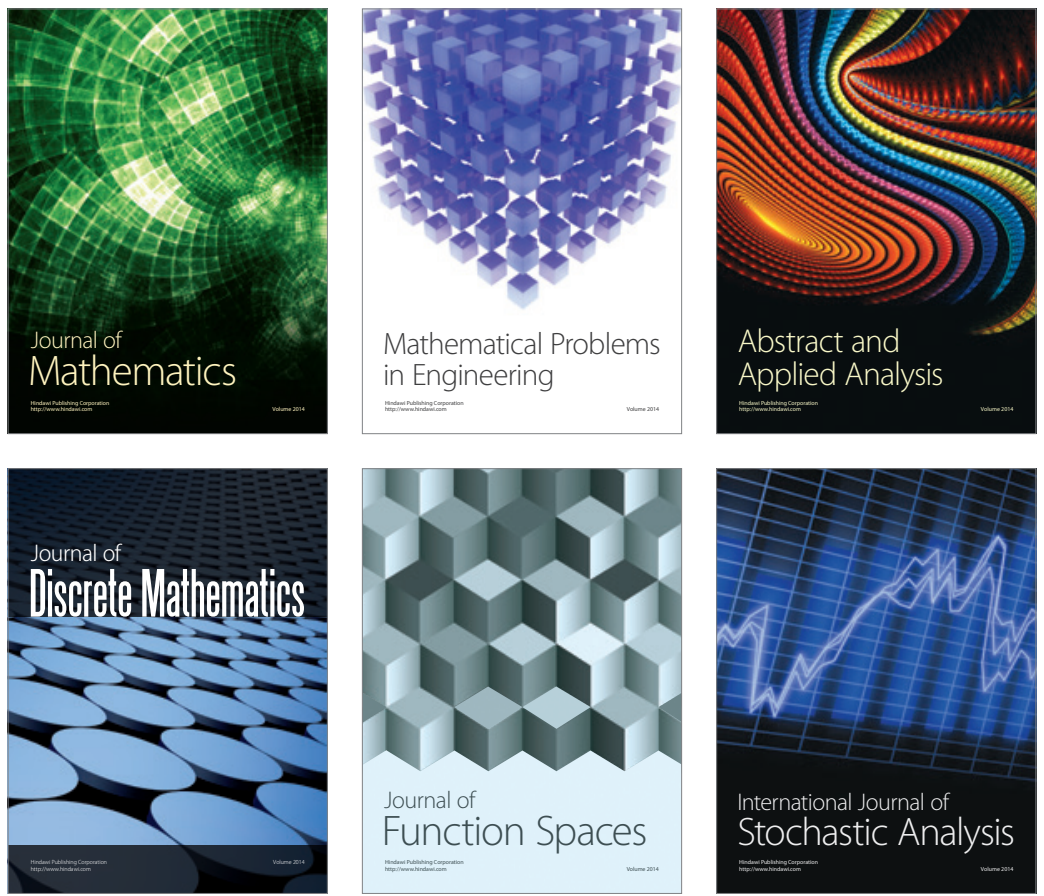

Journal of

Function Spaces

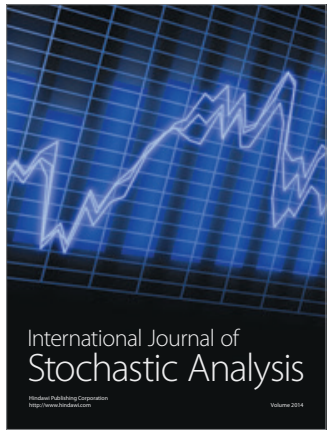

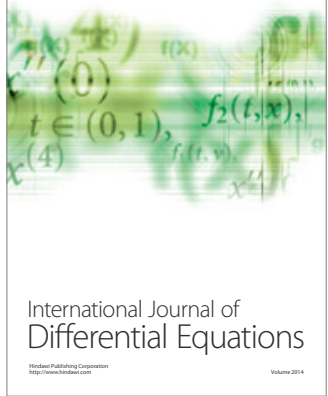
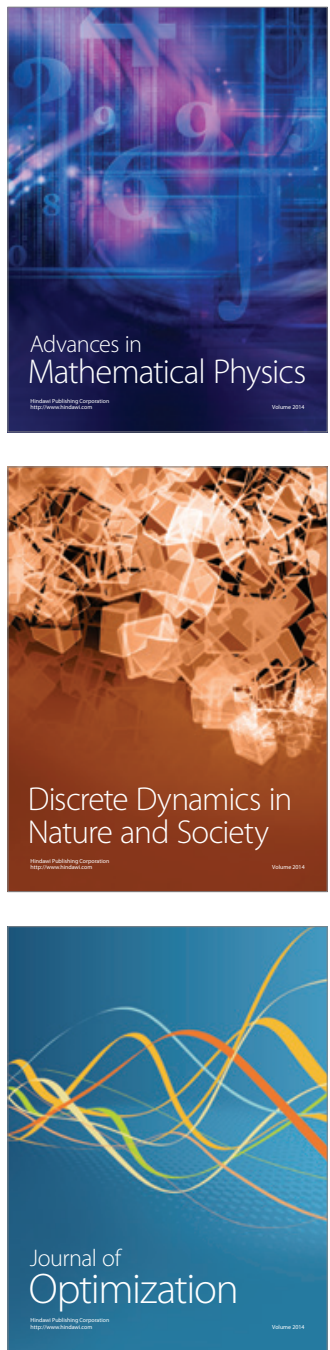